\title{
COGNITIVE REHABILITATION OF NAMING DEFICITS FOLLOWING VIRAL MENINGO-ENCEPHALITIS
}

\author{
Eliane C. Miotto ${ }^{1}$
}

\begin{abstract}
Objective: This case study describes the neuropsychological assessment and cognitive rehabilitation of a patient who developed word retrieval deficits for objects and people's names, following an episode of viral meningo-encephalitits. It shows the implementation and outcome of two techniques adapted to the patient's individual characteristics and context providing a more ecologically valid approach. Method: In the first technique, "verbal semantic association", the patient was required to describe what she knew about an object as a strategy to help her retrieve its name. In the second one, "face-name association" she was taught to apply a visual-imagery technique in order to retrieve relevant people's names. Results: Following the implementation of these procedures there was a decrease in the number of episodes of failure to retrieve objects and people's names in her everyday life context. Conclusion: The improvement found in the patient's ability to retrieve words is discussed in terms of the utility of cognitive rehabilitation programmes and cognitive models of language processing.
\end{abstract}

KEY WORDS: cognitive rehabilitation, naming deficits, viral meningo-encephalitis.

\begin{abstract}
Reabilitação cognitiva de deficits de nomeação após quadro de meningo-encefalite viral
RESUMO - Objetivo: Este estudo de caso descreve a avaliação neuropsicólogica e reabilitação cognitiva de uma paciente que apresentou déficits de evocação de palavras relacionadas a nomes de objetos e pessoas após episódio de meningo-encefalite viral. A implementação e evolução de duas técnicas adaptadas às características particulares e contexto da paciente são apresentadas e discutidas dentro de uma abordagem ecologicamente válida. Método: Na primeira técnica utilizada, "associação semântica verbal", foi solicitado à paciente que associasse o maior número possível de idéias ao objeto em questão como uma forma de estratégia para ajudar na evocação do respectivo nome. Na segunda, "associação nome-face", a paciente foi instruída a aplicar uma técnica de imaginação visual como estratégia para a evocação de nomes de pessoas. Resultados: Após a implementação destas técnicas, houve diminuição significativa dos episódios de falha de evocação de nomes de objetos e pessoas. Conclusão: Os resultados obtidos associados a uma melhora na capacidade de evocação de palavras são discutidos em termos da utilidade de programas de reabilitação cognitiva e modelos teóricos cognitivos de processamento da linguagem.
\end{abstract}

PALAVRAS-CHAVE: reabilitação cognitiva, déficits de nomeação, meningo-encefalite viral.

It is well known that neuropsychological deficits can result from an episode of viral meningo-encephalitis ${ }^{1,2}$. The latter is usually defined as an inflammation of the brain and its meninges, and herpes simplex virus is the most commonly isolated virus. The quality of survival of these patients ranges from complete recovery without any cognitive or neurological deficits to severe impairment. The incidence and severity of residual disturbances usually depend on the differing virulence between viruses and the age of the patients. The clinical presentation, which may include memory and language problems are very common cognitive deficits assessed by clinical neuropsychologists. However, if the clinical presentation is associated with only mild cognitive deficits such patients may not be able to attend an appropriate rehabilitation unit, the majority working with more disabled patients, or may have to face long waiting lists. Therefore, the need to develop cognitive rehabilitation programmes for short periods of time that tackle such deficits has increased in the clinical practice. The present case report describes the neuropsychological assessment and subsequent clinical intervention of a patient who presented with selective naming deficits following viral meningo-encephalitis. Cases of 'pure anomia' and attempts at remediating such deficits have previously been reported $^{3-6}$. However, although there is some general

\footnotetext{
'Department of Neuropsychology, The National Hospital for Neurology and Neurosurgery (Queen Square, London, WC1N 3BG, UK).

Received 18 April 2001, received in final form 27 August 2001. Accepted 10 September 2001.
} 
agreement that naming efficacy improves after treatment, the issue of whether results are item-specific or generalised is still controversial. A number of studies have reported a widespread improvement after naming treatment including untreated words ${ }^{7,8}$. In contrast, other studies have shown an improvement on only treated items and occasionally untreated words in the same semantic category as the treated words ${ }^{5,4}$.

Cognitive models of language processing have been used to guide a number of treatments in aphasias and to provide a more principled approach to this issue. One of these cognitive models suggests that lexical form is represented through modalityspecific components separately for input and output processing ${ }^{9-12}$. When visual perceptual deficits are excluded, a failure to name an object could result from damage to the semantic system or phonological output lexicon ${ }^{6}$ (Fig 1). In the case of a breakdown at the level of the semantic system, the naming deficits expected would probably be a consequence of poor semantic or conceptual information failing to activate the required lexical form. Incorrect responses would be expressed as semantic related words. If the breakdown occurs at the level of the phonological output lexicon, the incorrect responses would result from adequate semantic or conceptual information not being able to access the required lexical representation or failing to activate unavailable lexical representations resulting in omissions or semantic errors ${ }^{6,11}$. For example, damage to the lexical form 'scissors' would prevent its adequate semantic representation (made of metal, long, inanimate, used to cut objects, sharp edge, etc.) from activating the correct response. However, because the lexical entries related in meaning to 'scissors' are activated, the semantic representation of 'scissors' could still activate semantically related forms such as knife, blade, plies, etc. and produce semantically incorrect responses. Therefore, a breakdown at the level of the semantic system or the phonological output lexicon could result in semantically related errors. What differentiates these deficits is that when damage occurs to the semantic system, semantic errors would parallel deficits in comprehension. If the damage takes place at the level of the phonological output lexicon the lexical form that produced semantic errors or omissions in naming is expected to be satisfactorily comprehended ${ }^{6,11}$. Identification of these different forms of anomia through evaluation in the context of a cognitive model has led to the development of treatment programmes on proposed sources of breakdown within the model.

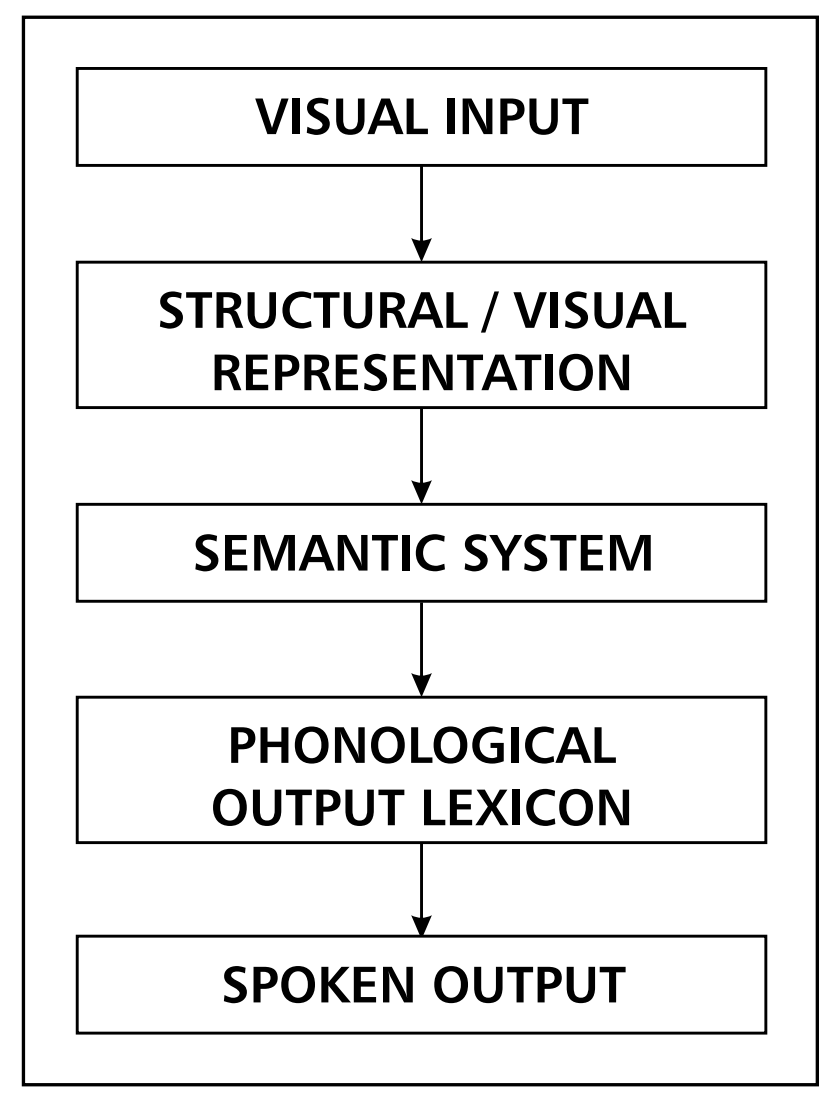

Fig 1. Schematic representation of the cognitive processes involved in oral naming (adapted from Miceli et al., 1996).

The current study reports on a patient who developed selective word retrieval deficits mainly associated with people and objects' names. It is aimed to describe the planning and implementation of treatment goals focused on the main difficulties encountered by her in everyday life situations and the outcome in light of cognitive neuropsychological models. In particular, the hypothesis of damage at the level of the phonological output lexicon was investigated. The treatment approach suggested aimed at providing a more ecologically valid attempt to address difficulties found in real life. The study also demonstrates the potential for implementation of short period of cognitive rehabilitation in clinical practice and the possible contribution to the quality of the patient's life.

\section{METHOD}

\section{Case history}

The patient (ME) is a 66 year old woman, right handed, who 14 months previously was admitted to a local General Hospital for a 2 week period as an inpatient. She had suffered a severe attack of viral meningo-encephalitis of unknown cause and was expected to make a complete 
Table 1. Neurospychological test results.

\begin{tabular}{|c|c|c|c|}
\hline \multirow[t]{7}{*}{1.} & \multicolumn{2}{|l|}{ WAIS-R } & Age Scaled \\
\hline & \multicolumn{2}{|l|}{ Information: } & 8 \\
\hline & \multicolumn{2}{|l|}{ Digit Span: } & 10 \\
\hline & \multicolumn{2}{|l|}{ Vocabulary: } & 10 \\
\hline & \multicolumn{2}{|l|}{ Arithmetic: } & 13 \\
\hline & \multicolumn{2}{|c|}{ Comprehension: } & 12 \\
\hline & \multicolumn{2}{|c|}{ Similarities: } & 11 \\
\hline & \multicolumn{2}{|c|}{ Picture completion: } & 10 \\
\hline & \multicolumn{2}{|c|}{ Block design: } & 11 \\
\hline & \multicolumn{2}{|c|}{ Object assembly: } & 8 \\
\hline & \multicolumn{2}{|c|}{ Digit symbol: } & 15 \\
\hline & \multicolumn{3}{|c|}{$\mathrm{VIQ}=102 \mathrm{PIQ}=106$} \\
\hline 2. & \multicolumn{3}{|l|}{ NART-R } \\
\hline & \multicolumn{3}{|c|}{ Estimated pre-morbid VIQ = 102} \\
\hline \multirow[t]{3}{*}{3.} & \multirow{3}{*}{$\begin{array}{l}\text { Story Recall } \\
\text { Immediate: } \\
\text { Delayed: }\end{array}$} & AMIPB Form 1 & \\
\hline & & 28 (25-50 $\left.{ }^{\text {thoile }}\right)$ & \\
\hline & & 26 (25-50 thoile) & \\
\hline \multirow[t]{4}{*}{4.} & List Learning & AMIPB Form1 & \\
\hline & Total A1-A5: & 40 (25-75 thoile) & \\
\hline & A6: & 7 (25 thoile) & \\
\hline & B: & 5 (50 thoile) & \\
\hline \multirow[t]{3}{*}{5.} & Figure Recall & AMIPB Form1 & \\
\hline & Immediate: & 45 (50 thoile) & \\
\hline & Delayed: & $46\left(50-75^{\text {tho }} \%\right.$ ile $)$ & \\
\hline \multirow[t]{3}{*}{6.} & \multicolumn{3}{|c|}{ Graded Naming Test } \\
\hline & \multicolumn{3}{|c|}{ Total Correct: $\quad 15 / 30$ (50\% correct responses) } \\
\hline & \multicolumn{3}{|c|}{ Re-assessment: $24 / 30$ ( $80 \%$ correct responses) } \\
\hline \multirow[t]{3}{*}{7.} & \multicolumn{3}{|c|}{ Oldfield-Wingfield } \\
\hline & \multirow{2}{*}{\multicolumn{3}{|c|}{ Re-assessment: $28 / 30$ (93\% correct responses) }} \\
\hline & & & \\
\hline \multirow[t]{2}{*}{8.} & \multicolumn{3}{|l|}{ FAS } \\
\hline & \multicolumn{3}{|c|}{$F: 14, A: 13, S: 17$} \\
\hline 9. & Trial Making $\mathrm{T}$ & & \\
\hline & A: & $41 \mathrm{sec} .\left(25-50^{\text {thoile }}\right)$ & \\
\hline & B: & 82 sec. (75 - $\left.90^{\text {thoile }}\right)$ & \\
\hline
\end{tabular}

recovery. A CT brain scan performed during this time showed no brain abnormalities. After her admission as an inpatient she went on holidays for 6 weeks to another country visiting some friends. During this period she noticed problems in remembering the names of objects and people and these problems were even more apparent to her hosts. These difficulties were still present 12 months later when she did not recognise who had sent her Christmas Cards from the first name alone and had to search her address book for the surnames. Other difficulties included, for example, going out for a meal and later asked to describe what she had eaten. In such circumstances she was able to visualise the dish but unable to name it. The same hap- pened with the names of people she knew well. She could recognise their faces but did not remember their names or, sometimes, where she knew the person from. She associated these difficulties with memory problems and expressed a great deal of concern and frustration about them. Frequently, when these problems took place she ended up being helped by her friends, for example producing the word that she could not remember. She had previously worked as a book keeper and since then became involved with a number of charity associations doing voluntary work in hospitals. Despite her cognitive difficulties, she had a very full life with different work and social activities. However, since her illness she found it more difficult to remember the names of the patients she worked with in the hospital whom she had known for a long time. In addition, she felt embarrassed when talking to her friends and not being able to retrieve the name of a particular object.

\section{Neuropsychological status}

A standard neuropsychological assessment was carried out on $\mathrm{ME}$ in order to ascertain the nature and extent of her cognitive deficits (see Table 1 for test results). Reassessment of her word retrieval skills took place around 4 weeks after the initial treatment and this will be discussed later. Throughout the testing session she was cooperative and well engaged with the tasks.

An estimation of her pre-morbid optimal level of functioning based on the National Adult Reading Test-Revised (NART-R), 2nd Ed. ${ }^{13}$ placed her within the average range. Her current level of intellectual functioning was assessed by the Wechsler Adult Intelligence Scale-Revised (WAISR) ${ }^{14}$ and found to be within the average range for both the Verbal and Performance scales of the WAIS-R. These results were in line with her pre-morbid optimal level of functioning. Three subtests of the Adult Information Processing Battery (AMIPB) ${ }^{15}$ namely, Story Recall, List Learning and Figure Recall were used to test her memory and learning functions. Her results on these subtests were within the expected average range. Word retrieval skills assessed on the Graded Naming Test ${ }^{16}$ and on the OldfieldWingfield Object Naming Test ${ }^{17}$ were impaired. It should be noted that she was able to provide the correct semantic information about all the objects she failed to name. On these tests, her main type of response was "I know the name...l just cannot remember it now". In addition to formal testing, word finding difficulties were observed in spontaneous conversation. Language comprehension assessed on the Token Test ${ }^{18}$ and the Vocabulary subtest of the WAIS-R was within normal limits. There was no evidence of repetition or spelling errors of single words as assessed on the Word Repetition Test and Oral Graded Difficulty Spelling Test (23/30). On a number of tests sensitive to frontal executive dysfunction her performance was in the average/high average range. Results on verbal fluency assessed by the Controlled Oral Word Association Test (FAS) ${ }^{19}$ were in the high average range. Her mental 
'set-shifting', conceptualisation and visuo-motor tracking abilities tested on the Trail Making Test ${ }^{20}$ were in the average (Part A) and high average range (Part B).

\section{RESULTS}

\section{Test interpretation}

The results of the neuropsychological tests administered together with the interview with ME addressed a number of relevant issues which will be discussed below. Based on the results of her premorbid and current level of intellectual functioning there was no evidence to suggest intellectual decline. This was consistent with her description of no changes in terms of her general abilities and everyday life functioning. She is a very active lady engaged on social activities and voluntary work on a daily basis. She had no difficulties in performing these activities and found them on the whole enjoyable. The results of the memory tests showed no abnormalities and were all within the average range. This was relevant in terms of understanding her difficulties in retrieving people and objects' names. The hypothesis of an organic memory disorder underlying these difficulties has no support based on these results. Her age scaled scores on subtests involving span of attention and concentration, such as Digit Span and Arithmetic, were within the average and high average range, respectively. These results showed a normal capacity to register and encode verbal and non-verbal material. Results on tests sensitive to frontal executive dysfunction were in the average or high average range. This is in line with her everyday level of functioning. For example, in order to keep up with all her appointments, organise and execute the various activities that she is involved with and be appropriate in social contexts it is fundamental that her executive skills are intact. Her performance on the language tests showed a more inconsistent pattern. Her comprehension, repetition and spelling skills of single words were within normal limits. However, when assessed on two naming tests (Graded Naming Test and the Oldfield-Wingfield Object Naming Test) her performance was impaired. This could reflect a specific deficit as a consequence of her meningo-encephalitis. In summary, the results of the neuropsychological assessment together with the interview with ME were not suggestive of general intellectual decline or memory deficit, ruling out the involvement of an organic memory disorder as the explanation for her current difficulties. Rather, her difficulties could be explained by selective naming deficits based on her impaired performance on naming tests and word finding difficulties occasionally observed on her spontaneous conversation. In this context, her comprehension and semantic knowledge about the unnamed objects were well preserved.

\section{Cognitive rehabilitation}

The treatment goals were focused on the patient's main difficulties encountered in everyday life situations. Based on ME complaints of difficulties in retrieving names of objects and the names of the patients she worked with at the hospital, the use of specific strategies was initially discussed with her to assess her interest and to provide realistic information about the use of these strategies. The emphasis on amelioration or compensation for cognitive difficulties instead of restoration of function ${ }^{21}$ was outlined. After this initial discussion ME expressed her interest in learning and practising the use of these strategies. The total period of cognitive rehabilitation lasted for 6 weeks including 10 days for baseline measure, 32 days for implementation of the clinical procedures and 1 day follow up. During this period she was seen four times for one hourly session.

Baseline measure - For the first ten days ME was instructed to record in a diary the number of times she could not retrieve the name of a particular person or object. Each day on the diary was divided into three periods including morning, afternoon and evening. Within these periods she recorded the number of episodes in which she could not retrieve the name of a person by the letter ' $P$ ' (person) and an object indicated by the letter ' $O$ ' (object). In total, there were eighty episodes of forgetting people's names and sixty episodes of forgetting objects' names. The average rate per day was 8 episodes for people's names and 6 episodes for objects' names (Table 2).

Clinical procedures - Subsequently, two different procedures were adopted during the intervention period including visual imagery and verbal semantic association. Visual imagery ${ }^{22}$ can be defined as "remembering by pictures" 23 . One procedure designed specifically for learning names is the face-name association method. It usually includes four stages in which the subject is asked (1) to select a distinctive feature from the face of the person whose name is to be remembered; (2) to transform the person's name into one or two common nouns (e.g. "barber" for "Barbara"); (3) to link the distinctive feature and the transformed name in some way; and (4) 
Table 2. Mean number of daily episodes of failure to retrieve people and objects' names during baseline, clinical intervention and follow up.

\begin{tabular}{lcccc}
\hline & Baseline & Procedure 1 & Procedures 1 and 2 & Follow Up \\
\hline People's Names & 8 & 7.85 & 1.58 & 1 \\
Objects' Names & 6 & 1.85 & 1.47 & 2 \\
\hline
\end{tabular}

on meeting the person whose name is to be remembered, to select the distinctive feature, retrieve the image and recall the name ${ }^{24}$. These procedure has successfully been used in patients with brain injury $^{22,24}$. It should be noted that the visual imagery and verbal association procedures employed in ME's case have been adapted to her particular needs and level of functioning. The verbal semantic association strategy applied for objects involved her spontaneously to produce as many verbal associations as possible about the object to be remembered in order to facilitate its triggering ${ }^{25}$. This could be applied to many situations in her case since she could often visualise the object in question but was unable to retrieve its name. She was asked to produce as many associations as possible within a period of five minutes. If she was still unable to retrieve the name of the object she would record in her diary the number of times it had happened. It should be noted that she carried on making records of the number of daily episodes of failure to retrieve people and objects' names throughout the intervention period in order to identify whether or not an improvement had taken place in comparison to her baseline measure.

Procedure 1 - After the baseline measure was completed, Procedure 1 was introduced. The verbal semantic association strategy was implemented first since it was a less complex procedure and also because she was still taking photographs of the people that she would like to apply the face-name association strategy. Based on the episodes of failure in retrieving objects' names described during the baseline measure one example was selected and used as practice trial. She described having difficulties in recalling the word 'broccoli' on one occasion although she was able to visualise it in her mind. She was asked to produce as many associations as possible with its image, such as "it is green... looks like a tree...you can cook it". After being trained in producing these associations she was asked to apply the same procedure every time she had difficulties in remembering an object's name. We agreed that she should try it for about five minutes and if she was still not able to retrieve the name when this time had elapsed, she would record this episode in her diary as a failure to remember an object's name. She was also instructed to advise her friends not to help her by providing the correct word.

Procedure 2 - Two weeks later a number of photographs of people she had difficulties in remembering the names were brought and the face-name association procedure introduced. These pictures were mainly of patients from the hospital she was doing voluntary work. Two photographs with the person's name written down on the back were selected. For the first one, she was initially asked to say the name of the person or read it aloud if she could not remember it. She was then asked to provide as many associations as possible by looking at the person's face and think about different personal features. Subsequently, she was asked to produce a link between the name and surname of the person with the associations mentioned above. For example, for the first name she described "She is a very quiet and silent person who does not talk to anyone unless she has been approached. She reminds me of a close friend who has the same name and is also quiet". For the surname, she and I produced an association which linked the sound of the surname with a telecommunication company and the fact that a 'line' seems to be needed to get in touch with this person. The same procedure was applied for the second photograph. Once it became clear that she understood how to use this procedure she was asked to apply it to the various photographs of people she took previously. During the following two weeks she was asked to carry on making records on her diary of the daily number of episodes of failure to retrieve objects and people's names. Comparisons were subsequently made with her baseline measure (Table 2 , Fig 2).

Treatment outcome - Around four weeks after Procedure 1 was introduced, ME attended a follow up session. We discussed various issues related to the use of the strategies including how she man- 


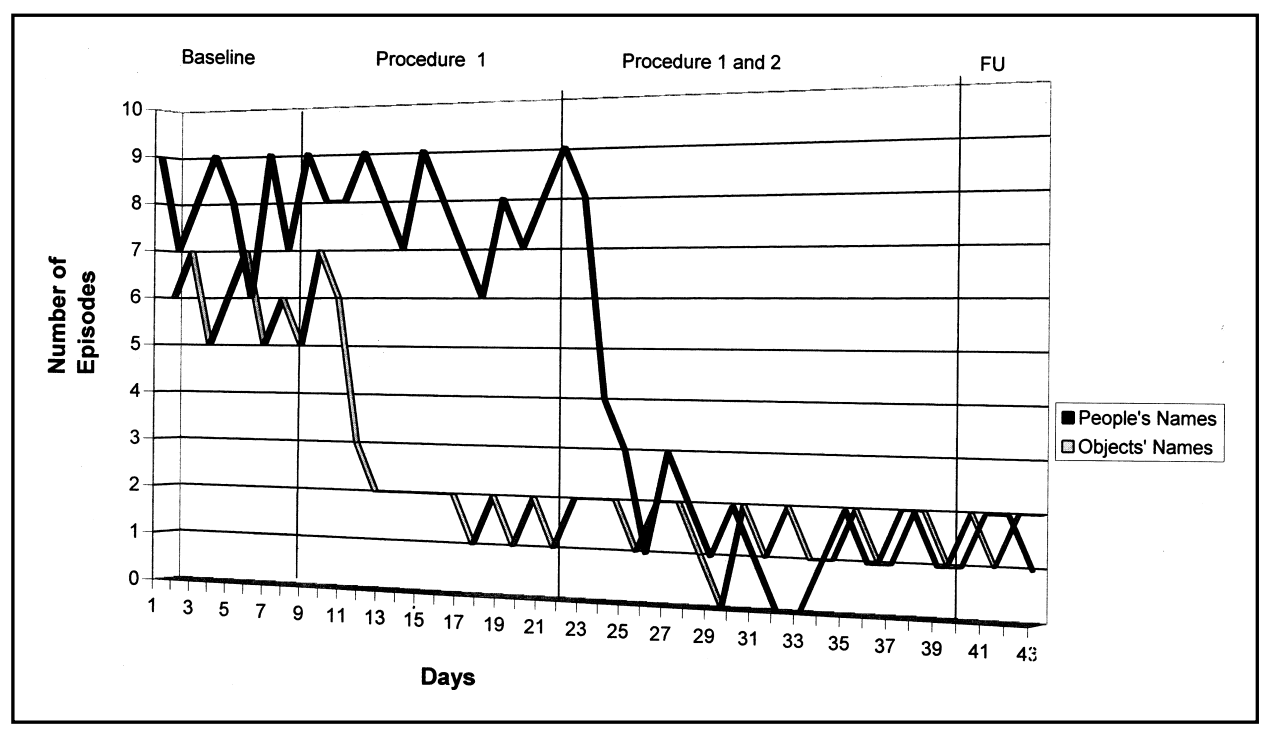

Fig 2. Episodes of failures to retrieve people and objects names.

aged, difficulties encountered and how she dealt with them. The Graded Naming and Oldfield-Wingfield tests were re-administered with the results showing a considerable improvement in her performance in comparison to her initial assessment (see Table 1). Although practice effects could not be completely ruled out as possible explanation for this improvement, it was noted that she did apply the learned strategies whilst doing these tests. In the same vein, there was substantial evidence of a decrease in the number of episodes of failure to retrieve people and objects' names during the implementation of the clinical procedures and follow up as ascertained by her daily records on her diary (Table 2, Fig 2). Overall, she found the strategies very helpful, felt much less embarrassed in social situations and expressed her interest in continuing to use them.

\section{DISCUSSION}

This case report described a patient who presented with difficulties in retrieving objects and people's names as residual deficits following an episode of viral meningo-encephalitis. The neuropsychological assessment provided relevant information regarding her cognitive functioning and formed the basis for an appropriate clinical intervention. Following the two procedures adopted as part of her cognitive rehabilitation programme, naming performance improved in everyday life situations.

On formal tests of word retrieval skills this improvement was also observed. In addition, it increased her self-confidence and her sense of embarrassment in social contexts diminished. This improvement can- not be attributed to spontaneous recovery since she was seen in the chronic stage of her illness. The pattern of her cognitive performance and the improvement on her word retrieval skills following a period of treatment can perhaps be better understood when cognitive models of language processing are considered. In order to name an object, the early stages of visual processing result in the development of object representations which activate a set of stored object recognition units in the semantic system. Subsequently, these semantic representations activate the phonological output lexicon for the eventual oral naming of objects (Fig 1) ),9-11. $^{6}$.

Based on ME's normal ability to comprehend and provide correct semantic information about the unnamed items, one would not expect a breakdown at the semantic level. Instead, it is possible that damage to the phonological output lexicon or to the mechanisms that allow access to such representations have occurred as a result of her illness. Treatment in such circumstances should facilitate unavailable lexical representations to become newly available for output. The treatment outcome reported in this study suggests that training may facilitate a process of lexical retrieval. In this context, a number of well preserved cognitive functions in ME have possibly played an important role in this process. For example, the procedures adopted in her treatment were associated with the generation of strategies, comparative analysis of visual and verbal information, selection and monitoring of responses and the ability to remember a sequence of stages during the implementation of these procedures. These cognitive 
activities have probably placed particular demands on frontal executive, memory and visual perceptual functions which were intact in $\mathrm{ME}^{26,27}$. At this stage it is not clear whether her ability to remember names specially object names has improved as a result of the implementation of the strategies or because she spent more time searching for a name, i.e., five minutes in Procedure I. In order to investigate this issue, a further procedure in which she would be required to retrieve the names of objects and people within a period of time without using any strategy could be applied. Unfortunately it was not possible to implement the latter due to time constraints. ME did not have a significant psychological disorder to be addressed on top of her cognitive problems.

She reported feeling very frustrated with these difficulties but there was no evidence of symptoms of depression or anxiety. She had a large number of friends who she visited and went out with on a weekly basis. Therefore, it is possible that this social network together with the support of her children played an important role in her ability to cope with the emotional distress caused by her cognitive difficulties. Nevertheless, her determination and effort employed during the intervention period were evidence of her fortitude and emotional resources.

In summary, this study demonstrated that a short period of cognitive rehabilitation programme can be very helpful in alleviating marked specific neuropsychological deficits such as anomia. The approach adopted here has attempted to bridge the gap between laboratory treated items and real life word retrieval deficits by providing specific strategies to be implemented in everyday life situations. More ecologically valid approaches to similar or other neurospychological deficits warrant further investigation.

\section{REFERENCES}

1. Parkin A, Hunkin N, Squires E. Unlearning John Major: the use of errorless learning in the reacquisition of proper names following herpes simplex encephalitis. Cognitive Neuropsychology 1998;15:361-375.

2. Barbarotto R, Capitani E, Laiacona M. Naming deficit in herpes simplex encephalitis. Act Neurol Scand 1996;93:272-280.
3. Kay J, Ellis AW. A cognitive neuropsychological case study of anomia: implications for psychological models of word retrieval. Brain 1985;100:613-629.

4. Howard D, Patterson KE, Franklin S, Orchard-Lisle VM, Morton J. The treatment of word retrieval deficits in aphasia: a comparison of two therapy methods. Brain 1985;108:817-829.

5. Hillis AE. Efficacy and generalisation of treatment for aphasic naming errors. Arch Phys Med Rehab 1989;70:632-636.

6. Miceli G, Amitrano A, Capasso R, Caramazza A. The treatment of anomia resulting from output lexical damage: analysis of two cases. Brain \& Language 1996;52:150-174.

7. Wiegel-Crump C, Koeigsknecht RA. Tapping the lexical store of the adult aphasic: analysis of the improvement made in word retrieval skills. Cortex 1973;9:411-418.

8. Seron X, Deloche G, Bastard V, Chasin G, Hermand N. Word-finding difficulties and learning transfer in aphasic patients. Cortex 1979;15:149-155.

9. Morton J, Patterson KE. A new attempt at an interpretation, or an attempt at a new interpretation. In Coltheart M, Patterson KE, Marshall JC (eds.) Deep dyslexia, London: Routledge and Kegan Paul, 1980:57-65.

10. Shallice T. Neurological impairment of cognitive processes. Br Med Bull 1981;37:187-192.

11. Caramazza A. Some aspects of language processing revealed through the analysis of acquired aphasia: the lexical system. Annu Rev Neurosci 1988;11:395-421.

12. Hillis AE, Caramazza A. Mechanisms for accessing lexical representations for output: evidence from a category-specific semantic deficit. Brain \& Language 1991;40:106-144.

13. Nelson HE, Willison JR. National adult reading test (2.Ed) . Windsor: NFER-Nelson, 1991.

14. Wechsler D. The Wechsler adult intelligence scale - revised. New York: Psychological Corporation, 1981.

15. Coughlan AK, Hollows SE. The adult memory and information processing battery. Leeds. St James Univ Hospital, 1985.

16. McKenna P, Warrington EK. Graded naming test manual. Windsor: NFER-Nelson, 1983.

17. Oldfield RC, Wingfield A. Response latencies in naming objects. Q J Exper Psychol 1965;17:273-281.

18. De Renzi E, Vignolo LA. The Token Test: a sensitive test to detect disturbances in aphasics. Brain 1962;85:665-678.

19. Benton AL. Controlled oral association test in differential behavioral effects in frontal lobe disease. Neuropsychologia 1968;6:53-60.

20. Army Individual Test Battery. Manual of directions and scoring. Washington, D.C.: War Department, Adjutant General's Office, 1944.

21. Harris JE, Morris PE. Everyday memory, actions and absent mindedness. London: Academic Press, 1984.

22. Jones M. Imagery as a mnemonic aid after left temporal lobectomy: contrast between material specific and generalised memory disorders. Neuropsychologia 1974;12:21-30.

23. Wilson B, Moffat, N. Clinical management of memory problems. London: Croom Helm, 1992.

24. Wilson B. Rehabilitation of memory. London: The Guilford Press, 1987.

25. Deelman BG, Berg IJ, Koning-Haanstra M. Memory strategies for closed head-injured patients: do lessons in cognitive psychology help? In Wood R and Fussey I (eds.) Cognitive rehabilitation in perspective. London: Lawrence Erlbaum Associates, Publishers, 1994.

26. Miotto EC. Abordagem neuropsicólogica dos lobos frontais. Rev Assoc Bras Psiquiatria ABP-APAL 1994;16:52-56

27. Miotto EC, Polkey CE, Bullock P, Morris RG. Spatial working memory and strategy formation in patients with frontal lobe excisions. Cortex 1996;32:613-630. 